\title{
Chemistry and Food Science
}

$\mathbf{N}$ the opening paper of a symposium on 1 "Chemistry and Food Science" in Section B (Chemistry), held at the Blackpool meeting of the British Association, Dr. Leslie Harris, of the Cambridge Nutritional Laboratory, spoke of a 'food cycle', analogous to the 'nitrogen cycle' of the chemist. To explain what was meant by the food cycle, he said that food in the first place must be collected or gathered; then it may undergo some manufacturing process; next it may be transported (by sea, rail or road); after which it may be preserved or stored in the cold; before at last it is prepared for the table and eaten. To complete the 'food cycle', it has to be remembered that food, or some part of it, is ultimately converted into manure, and so fertilization is brought into the picture-and with fertilization goes food production, the raising of crops and the rearing of farm animals. In each of these stages of the food cycle, the work of the chemist has been of service to the community, and in the discussion each stage was in turn dealt with by an expert. It might be thought that the logical order is to discuss first food manufacture, and then transport and storage and finally nutrition. On the other hand, all these complicated processes are of no avail, if the final product fails to nourish-so that nutrition must be the final criterion, and may be given pride of place.

On the purely chemical side, as Dr. Harris pointed out, a great body of knowledge has been won in the science of food and nutrition. For example, what were formerly mysterious and intangible 'antiscorbutic' or 'antirachitic' properties in foodstuffs have been shown to be due to 'vitamins', still unidentified and given only vague descriptive letters, C, D, etc. Recently, the chemist has been able to reach one of his final goals by determining the structural formulæ of the vitamins (or five of the better known of them, at least), and in more than one instance he has even synthesized them in the laboratory. The consequences of such discoveries have not been insignificant. For example, the pharmacologist or clinician is now able to prescribe an exact dose consisting of a given number of International Units of an accurately standardized synthetic vitamin. But perhaps more important is the fact that the science of nutrition is now placed on a rational, logical basis instead of being an arbitrary, empirical and rule-of-thumb art. We can now speak with certainty and precision about matters which before, since they lacked formal proof, were open to dispute or disbelief.

\section{The Science of Nutrition}

The next point raised was that it is a mistake to consider food and nutritional science too exclusively from the chemical angle. Nutrition is a biological process, and therefore can only be adequately studied by the combined methods of biochemistry and biophysics, of physiology and pathology, etc. No progress would have been possible for the pure chemist in his effort to solve nutritional problems without the aid of biological technique, such as animal-feeding tests, biological assays, etc. This is the justification for the existence of that highly trained specialist, the nutritionist-who, to be competent, must needs use the methods not only of chemistry and physics but also those of various biological sciences. In addition, we are beginning to realize that nutrition as a social science is inextricably bound up also with agriculture, and no less with economics.

\section{Prevalence of Malnutrition}

In conclusion, Dr. Harris said that as a main function of the British Association is to examine "the services of science to the community", the present problem is to inquire how far the science of food and nutrition has served the needs of the people and, more important, how much room there still is for improvement. What constitutes an adequate diet, and how far is it attained in practice? For the present purpose it is not necessary to consider the nutritional needs of the human individual from the more technical aspect -that is, the requirement for given food con. stituents, as fats, proteins, vitamins, etc. It is sufficient to point to the common errors of diet as met with in Great Britain, for example, inadequacy of such 'protective foods' as milk, fruit and vegetables.

How can the position as it exists in Britain at the present time be summed up ? It is true that people are better nourished than they were (few are now unable to obtain sufficient energy or crude protein), but much remains to be done to furnish a sufficient supply of those accessory factors which are essential for health and optimum growth. In the past, it has been difficult to assess at all accurately the prevalence of malnutrition becanse of the lack of definite standards of reference: average weights and heights for different age groups are available, but these are not the optima to be striven for. But recently progress in bio. chemical and other methods has provided specific 
diagnostic tests for partial deficiencies, and these are now being applied to random groups of the population and might with advantage be utilized on a large scale. Recent inquiries from various angles (for example, Sir J. B. Orr's from the economic side, and a number of surveys from the clinical side) are beginning to make it possible to assess fairly accurately the prevalence of specific disorders of malnutrition in Great Britain to-day.

It is no longer disputed that malnutrition (or 'sub-optimum nutrition') is widespread. It is due to some extent to ignorance, but much more to economic causes-there is still 'starvation in the midst of plenty'; such are the official conclusions of authoritative bodies which have been called upon to give their verdict, such as the International Committees recently appointed by the League of Nations, and by the International Labour Office.

Scientific evidence of malnutrition, presumptive or direct, has been obtained along several different lines: (1) economic (that is, insufficiency of money spent on food), (2) dietetic (inadequacy of food eaten), (3) medical (existence of disorders of deficiency), (4) sociological (comparison of the health standards of poorly-fed and better-fed social groups), and (5) experimental (improvement in health observed in controlled tests when the inadequate food is suitably augmented).

\section{The Preparation of Food}

The discussion of the scientific aspect of the preparation of food was very appropriately entrusted to Dr. L. H. Lampitt, head of the research department of an important catering firm.

Dr. Lampitt said that there have been at least five factors stimulating scientific investigations of food. These are-fear of food shortage, fear of war, national economic policies, commercial competition, and one general factor-the desire of man to search into the unknown.

"The coining of the word vitamin," claimed Dr. Lampitt, "has made the English stomachconscious in a new way, and while I personally cannot see that any nation gains much by that neurotic attention to food which is obvious in certain classes in more than one foreign. country, yet possibly an intelligent interest in food can be stimulated which will react to the betterment of the health of our people. One sometimes feels that the vitamin cult has perhaps blinded some of its votaries to the need of calories . . . and perhaps the inorganic salts will receive their due recognition in the near future."
Moreover, as Dr. Lampitt emphasized, people are apt to forget that palatability is a first essential in food, and that proper cooking, in its way, may be as important as a knowledge of calories and vitamins and inorganic salts. Mass production of food, in canning and preserving, and in restaurants, has necessitated the application of science by commercial firms to maintain the quality of food and to enable it to be kept for long periods of time. Thus it is comparatively simple for a chef to make a mayonnaise sauce; but its production in hundreds of gallons, so that the product will remain in good condition, no matter how badly treated by the retailer, and afterwards in the home, involves a whole series of problems which the chemist alone can solve. Mass production also introduces another factor, in the form of metallic contamination. None the less, the unfounded scaremongering about the contamination of food from aluminium cooking-vessels is altogether to be deprecated. Bacterial contamination is another matter, and is one of the most difficult and insistent problems in food industry. But thanks to the help of legislation and scientific investigations, the standard of purity of food in Great Britain is higher, Dr. Lampitt claims, than in many other countries which, in contrast with our own, have the most complete bureaucratic control.

\section{Food Preservation and Transport}

Numerous interesting points were briefly touched on in a paper by Dr. Franklin Kidd, head of the Low Temperature Research Station at Cambridge, which was read in his absence by Dr. Thomas Moran. For example, on the practical side, in the work on proteins, two problems have been solved. In the first place, it has been shown how even the toughest meats from old animals can be rendered tender by hanging for the right time at the right temperature. Conditions are now also understood for avoiding that hardening which may occur during preservation in a frozen condition. An important result of this discovery has been that summer catches of choice halibut from far northern waters may now be taken to any region of the earth and eaten at any season. With quick freezing and thawing, and holding at extremely low temperature, the herring gluts of to-day can be preserved and 'spread'. In these matters, as Dr. Kidd concluded, we are at the beginning of great changes in the structure and organization of the fish trade in all countries.

An important aspect of modern food science relates to the conditions of food transport, and these were discussed by Mr. T. Herbert, of the L.M.S. Railway Company. As he pointed out, improvements in refrigeration and chilling 
processes have created entirely new branches of overseas trade. At home, improved containers have been installed on the railways, and more compact and efficient freezing plant has been evolved. As a result the consumer has been able to receive quicker deliveries, fresher food and greater variety. A vivid impression was conveyed to the audience of the different problems which have already been solved by showing them lantern slides iliustrating the imposing provision made on board ship and on rail for the transport of such commodities as meat, bananas, etc.

\section{Social Implications}

That topics concerning nutrition and malnutrition are still liable to be controversial issues was apparent with the opening of the general discussion by the president of the Association, Sir Josiah Stamp, who pleaded for scientific definition of the terms used andstatistical treatment of conclusions, and emphasized that these questions have social and even political implications. How, he asked, can one define the "amount of money needed for an optimum diet" when a French housewife is able to manage on so much less than her English counterpart, or how is one to define the "amount of money available for food" when it depends on how much of it is spent on beer !

\section{Food Science and Agriculture}

Prof. H. G. Denham, who followed, spoke of the benefits which scientific research has rendered to agriculture in New Zealand, and Prof. W. J. Young, of Melbourne, paid a similar tribute on behalf of Australia. In New Zealand the use of superphosphate has enabled the farmer to put a cow on every acre instead of only one cow on three or four acres. As a result of the drop in its price, the consumption of butter has been greatly increased. In the same way, the consumption of milk might be raised with marked effects for good on many sections of the community. Another contribution of the chemist to agriculture and to food science is the discovery that borax cures a disease of Cox's orange apples. Another is that cobalt, not iron, is needed to secure New Zealand sheep against certain common infectious diseases. Both Prof. Denham and Prof. Young united in expressing their obligation to the work of the Low Temperature Research Station at Cambridge.

The value and indispensability of the contribu. tion of the analytical chemist to food science was the theme chosen by Dr. G. Roche Lynch, president of the Society of Public Analysts and other Analy. tical Chemists. As he pointed out, much of our "newer knowledge of nutrition" has its origin in the work of the public analyst in controlling the adulteration of food.

\section{Positive Economics of the Fungi}

$\mathrm{T}$ $\mathrm{HE}$ emphasis of the study of economic mycology is so much upon the negative side, the effect of fungi as producers of disease, that it is very stimulating to have the presidential address to Section K (Botany) of the British Association, delivered on September 10, deal with the beneficial activities of these organisms. Mr. J. Ramsbottom has collected very numerous examples where fungi are of positive value to the community, and his paper makes fascinating reading.

Perhaps the most obvious use of fungi is as articles of food. In addition to the common mushroom, blewits (Tricholoma personatum) and species of the genus Boletus (B. edulis and B. scaber) are eaten in Great Britain; but Mr. Ramsbottom also mentioned the use of Pholiota agerita and Polyporus tuberaster, of literary lore, the Canadian Grifolia (Polyporus) Tuckahoe, the Indian bread of America (Poria cocos), the blackfellow's bread of Australia (Polyporus mylittce) and various tropical species of the genus Lentinus. Three species of the larger fungi are cultivated by man, namely, the field mushroom, the shiitake (Cortinellus Shiitake) and Volvaria volvacea. A historical review of the development of mushroom culture finds a natural place in Mr. Ramsbottom's puper, and a consideration of modern methods of pure. culture also appears therein. Production of the shiitake has little horticultural similarity to mushroom growing. A pile of logs is sprinkled with powdered wood from previously infected material, or covered with straw mats bearing spores. The cultivation of Volvaria volvacea is less precise, for heaps of rice straw, chopped banana leaves, or other vegetable refuse, are merely watered with rice-wash or sugar-cane juice, and usually bear within a fortnight. There is an extensive cultivation of this fungus within the tropics.

Truffles (Tuber spp.) still occur in Great Britain, and Mr. Ramsbottom's paper contains an implicit invitation for field mycologists to follow the example of C. E. Broome, who, in the middle of last century, always used a rake upon his fungus forays, and found truffles from very numerous localities. 